\title{
THE ABILITY OF IMPROVING GIS MAP MODELING
}

DOI: http://dx.doi.org/10.18509/GBP.2015.18

UDC: 007:004]:528.9-048.32

\section{Associate Prof. dr Aleksandar Valjarević ${ }^{1}$}

Full. Prof. dr Dragica Živković ${ }^{2}$

${ }^{1}$ University of Kosovska Mitrovica Natural Science Faculty Department of Geography - Serbia

${ }^{2}$ Faculty of Geography University of Belgrade- Serbia

\begin{abstract}
Cartographic modelling has come as a result of spatial inventory as well as an attempt of displaying and saving data by modelling. Since prehistoric drawings on cave walls to the present day, the GIS modelling of today has made it possible for everything we find in our surroundings to be transformed into data or digitally displayed as digital maps, either as 2D, 3D models or data base. Geo information is a phenomenon directly or indirectly linked with a particular location on Earth and it has a geographic dimension. In global terms, the dimension includes natural disasters, pollution, global melt-down, tracking down the areas rich in ore, infrastructural management etc. In local sense, it involves cadastre and registries, ecology and environmental analyses, vegetation supervision etc, making the following creating possible: maps, information merging, concrete tasks visualization, complex problem solution and solution presentation. GIS has not replaced cartography; rather, it has had it improved because it allows to its users to make interactive enquiries, the research made by the user themselves, analyzing spatial information and sorting the data out. Managing the resources and having them function in the proper way and in full accord with global trends is today practically inseparable from geo-spatial data and technologies suitable for their updating, managing and manipulation. The possibility of winter tourism development in Kopaonik is shown in this work as one of the most popular tourist destinations in Serbia. Analyzing the topography within the scopes of Kopaonik National Park, the fields where it is possible to erect new ski slopes have been tagged in the programme Global Mapper v. 16.0.
\end{abstract}

Keywords: cartographic, modelling, digital, GIS, Kopaonik

\section{INTRODUCTION}

Today, it is impossible to separate modern societies, their development, functioning and resource exploitation compliant with global trends from geospatial data and technologies for their collection, manipulation and updating). A specific challenge within the economic development is represented through creating conditions where modern informational and communicational technologies allow knowledge acquisition as well as information creation spread and use.

By analysing the topography in the vincinty of Kopaonik National Park, new tracks can be marked. The work has investigated the areas suitable for slalom.Slalom is a real technical discipline, with the elevation difference among the tracks of 180 to 220 metres as the field slope varies from $33 \%$ to $45 \%$ [1]. 


\section{MATERIALS AND METHODS}

The programme Global Mapper v15 xx has produced some better solutions in relation to some previous versions of this software especially when it comes to the tools used in the tool bar as digitizers. Now the option in question offers better solutions as the tool set used in drawing a polygon as well as the calculation of measurement is far greater, while work with these is far simpler. In order to do more complex tasks with the digital modelling of Kopaonik mountain terrain, other GIS and online applications must be involved too, with Google Earth and Google maps or some such programmes [2].

\section{SATELLITE RECORDING INITIAL PHASE INSERTION}

On the internet page (http://www.usgs.gov/) [3], what is checked in the falling menu is the page. The portal contains the options showing data extensions which are downloadable in the download file function, all the server data are taken over from the satellite landsat 7 . Function search data by region is activated on opening the window, it is the page. That is opened. The page contains a search criteria option. The desired option, a toponym or a coordinate can be typed in prior to this, the field address place is checked in this case, the toponym Kopaonik is inserted in the function show. The falling function then displays all the files which stand in the search engine protocol as a link with the words Kopaonik. Even a more precise way to download particular data is label the key with the title data sets. In the function data sets search a particular toponym is typed in. For example, that is Kopaonik, when the particular toponym is typed in, what needs to be checked is the extension that needs to be converted after the download. The extensions offered by the portal are of a wide range. The noticeable extensions on offer are the following: aerial imaginary, avhrr, cal/val reference cites, commercial, declassified data, digital elevation, digital elevation, digital line graphs, digital maps, eo-1, geoglam, global fiducially, global forest observation initiative, global land survey, hcmm, jecam sites, land cover, land sat cover, land sat cdr, land sat legacy, land sat mrcl, lidar, nasa ldpaac collections, orbview-3, radar, vegetation monitoring. Some of the extensions are not available due to the assessment of data importance. What is selected is the extension of digital elevation file data. When the election is selected in the menu offered, the following files are concerned as an option aster global dem, gmted 2010, gtopo 30, gtopo hydro 1k, srtm, srtm void filled, srtem, water body data [4].

\section{DEM CALCULATION AND FLT FILE FUNCTION}

It is the file Aster Global DEM that is checked and the Kopaonik Mountain data file is downloaded. The menu results contain the data about Kopaonik Mountain. The file is shown in coordinates, and for Kopaonik they are,. This is the central coordinate of the Kopaonik massive. What is done next is the file download obtained within the DEM extension. The DEM in question is of the following 30x30 m resolution. When the file is transferred into a particular file, it is converted into Global Mapper $13.2 \mathrm{v}$ xx software in the function File Open, but the desired extension is checked in the software itself which is now DEM file extension. The entire file is downloaded. The size of the Kopaonik Mountain file indicates that it is a mountain massive is composed of different mountain chains, so it has to be limited to the boundaries of Kopaonik National Park. The software has automatically determined hypsometric belts and absolute heights through points. In the software function of the file checked, the function Generate Contours is labelled. The parameters of the contour lines likely to be displayed can be placed there. In the initial window, Contour Interval equidistance is labelled. The space between the contour lines 
to become and in the case of Kopaonik Mountain is 100 metres. The supply contour lines are labelled at 100 metres, as the major ones are at 200 metres over a better visibility. In the window called Elevation Range what is determined is the lowest point of the DEM file which does not change as the lowest point is 500 metres, the point from which distance is calculated by definition. The highest point is defined by the top called Pancicev Vrh, and it is 2017 metres. On this being done, all the contour lines are obtained from the point of 500 metres up to the top with the help of hypsometry. A particular DEM is obtained, too [5]. The boundary of Kopaonik National Park is not precisely determined so software has to be imported. For that purpose it is Google Earth that is in use. What is typed in the Search menu is Kopaonik National Park. On showing the entire national park, what is left to be derived is the boundary. In the function called Layers, there are fields where all national parks in the world, including their boundaries, can be checked. In the software falling menu, the option more is checked. The option then is checked is Park/ Recreation Areas. Now it is the Kopaonik National Park boundary that is shown. The file is saved, the very boundary in the local folders field [6].

\section{MODELLING BY USING GIS AND SLOPE OBTAINING IN DEM FROM 33\% TO 45\%}

On obtaining a DEM with particular boundaries, including hypsometry, contour lines, and all the geo spatial data, what remains to be done is modelling all the areas which stand for places of potentials for slalom tracks building and maintenance. An algorithm in Geo Mapper software is performed like the following: What is set is the Common Elevation supported file for the file to open.When the Generic ASCII Text File Import Options are open.What is checked is the option Elevation Grid from 3D Point Data and the OK button is clicked;Then in the next window all the metres are left and then the OK button is clicked;So in this way a DEM is inserted containing XYZ coordinates; On doing this, the DEM is placed on the slope shader, and then it is exported as an elevation grid format, the FLT grid is checked, it is then calculated in metres and checked in the window; The FLT grid file is inserted, and what is left is only the FLT grid file;Then it is only the Export SlopeDirection Values Instead of Elevation that is checked and the Degree of Elevation function. The we proceed with the Generate Contour Line function, but these are now the values of the expositions expressed in \%; it is then checked in the window, only Generate Contour Lines with Specified Height, and in the case that follows it ranges from $33 \%$ to $45 \%$; the FLT is inserted in the DEM as the function determinig the contour lines in degrees, from $33 \%$ to $45 \%$, is displayed [7]. The potential slalom areas are shown in blue (Figure 1). As the three potential slalom tracks are selected accoring to the area and length (Figure 2). 


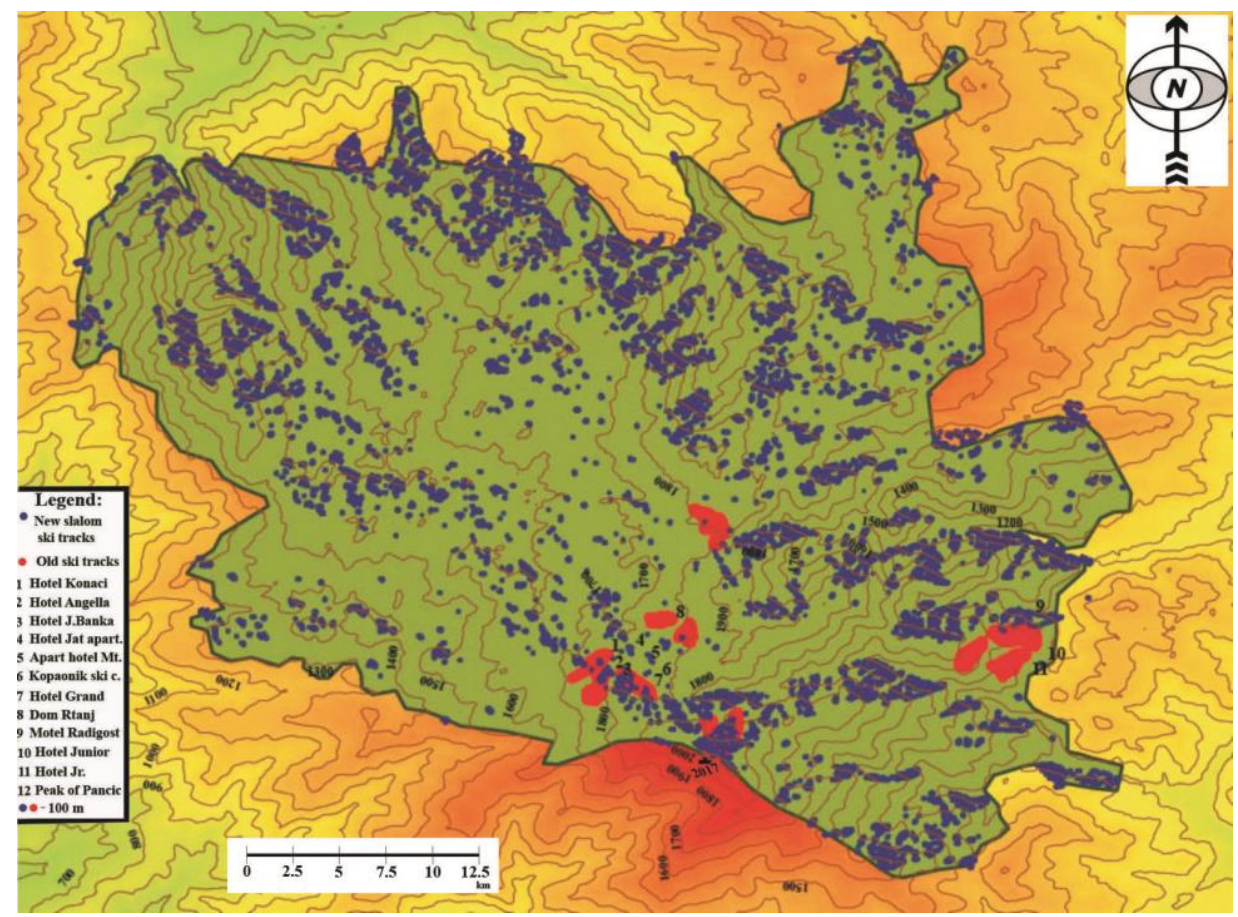

Figure 1. The National Park of Mountain Kopaonik with potential ski tracks for slalom $33-45 \%$ blue colors, and today ski tracks red colors.

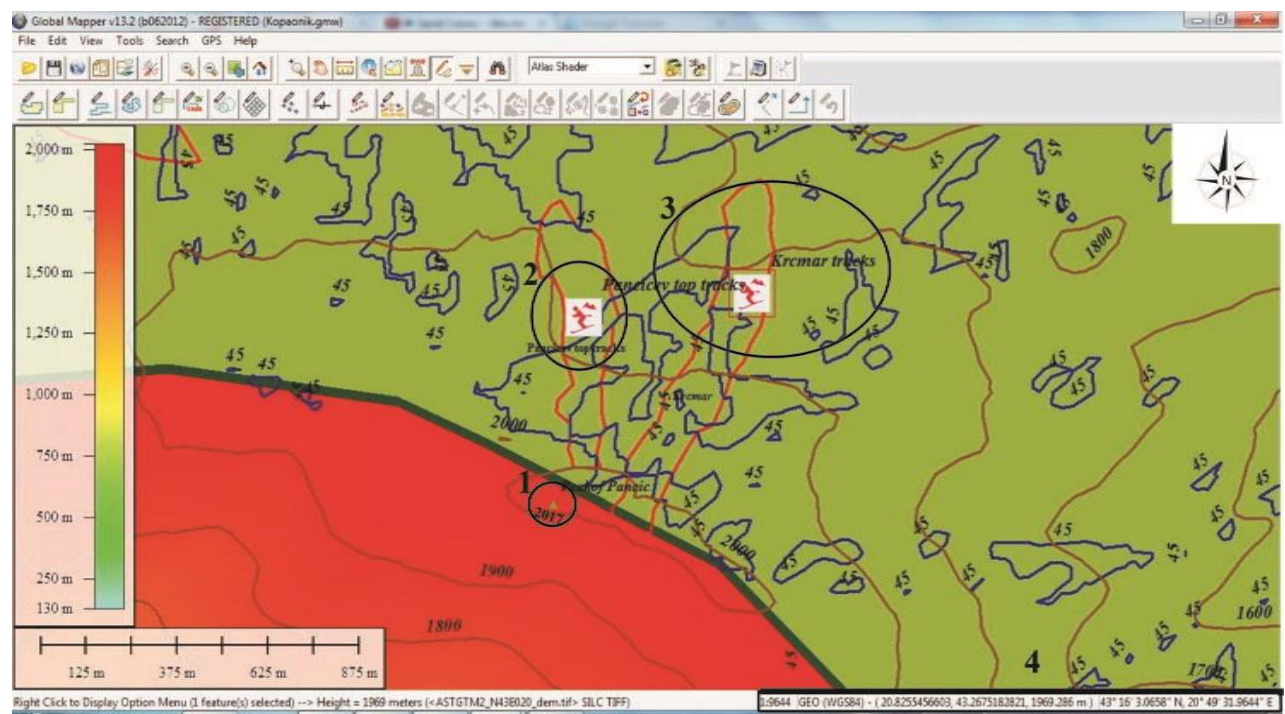

Figure 2. The most useful ski tracks of slalom in comparison with old ski trackson the Mountain Kopaonik near by Peak of Pancic. 1-Peak of Pancic, 2- The oldski tracks Pancic, 3-The new biggest ski tracks for slalom, 4-Modelling data derived from the GIS software GeoMedia Professional 6.1.

\section{RESULTS}

At this point the extension is exported in the KML file as the software Global Mapper $\mathrm{v}$ $15 \mathrm{xx}$ is imported. On the importation in the KML file, it remains to be transferred in the shp. file. That is done in the software Global Mapper. The boundary of Kopaonik National Park is permanently saved [8,9]. In the function Advance Feature Creation Options, the next option is checked by pressing the right click of the mouse, and the option is called Create New Area Features from the selected files. This is how an area is obtained from the line. The calculated area is 118.1 square kilometers or 11810 hectars, which equals the right values. In this way, the whole area of Kopaonik National Park has become geo- 
referential. Geographic coordinates on the likely geo-referential objects or which are probable to be placed on the map are downloaded from the data base called Geo Portal Serbia. These are hotels, restaurants, slopes, the national park ski objects all with the help of the function called Open Generic ASCII Text File (s), Global Mapper v15 xx, and all the files downloaded from the data base Geo Portal Serbia are opened, having been transferred into the txt file. All the objects are obtained on the map this way. By doing the geo reference of all the tracks from the analogue map called YUTA Kopaonik, it is the shp. file that is obtained, which is individually placed on the map and then checked in the function File Open shp.file. This is the way how all the geo spatial data of Kopaonik National Park are obtained (Table 1).

Table 1. Length of old skiing tracks, and length of skiing tracks for slalom.

\begin{tabular}{|l|l|}
\hline & Length \\
\hline Potential ski tracks for slalom & 10478 \\
\hline Old ski tracks & 55234 \\
\hline
\end{tabular}

\section{CONCLUSION}

Kopaonik is a mountain of unique features and of an exquisite natural potential; it is a volcanic massive of an immense area, genetically connected with an immense richness in ore, numerous geothermal springs, pastures, meadows, forests and incomparable climatic and topographic advantages for winter sport tourism [10]. Today's needs in the field of spatial planning, projecting and different forms of updating space demand that new technologies be applied. They make way for obtaining fast and reliable information and for the connection and interconnection of data of different sorts. A topographic analysis of Kopaonik National Park in Global Mapper 15 and GeoMedia Professional 6.1 marks the fields where it is possible to place for new slalom tracks. The application of GIS tools will contribute to a better and faster tourist development in terms of professional and computer support to developing plans.

\section{ACKNOWLEDGMENTS}

This work was financially supported by the Serbian Ministry of Education and Science project III44006, and also for project No. 1760019.

\section{REFERENCES:}

[1] Cees, G., Wesse, L., Derg, J., Kars, S., Peter, B., Willem, D. (2007). Integrating dynamic environment models in GIS: The Development of a Dynamic Modeling language. Transactions in GIS, 1(1), pp. 40-48.

[2] Yi, Qiang ., Delafontaine, M., Tijs, N., Birger, S., Guy, T., Philippe, M., Nico,W. (2012). Analysing Imperfect Temporal Information in GIS Using the Triangular Model. The Cartographic Journal, 49(3),pp. 265-280.

[3] htpp:// www.usgs.gov/pubprod/, retrieved 01 January 2015.

[4] Robert, E., Robert, B., Jan, T. (2001). Mapping wildland fuels for fire management across multiple scales: Integrating remote sensing, GIS, and biophysical modeling. International Journal of Wildland Fire, 10(4), 301-319.

[5] Keight, C., Gaydos J. (1998). Lose-comply cellular automation model and GIS: Longterm urban growth prediction for San Francisco and Washington. International Journal of Geographic Information Science, 12(7), pp. 699-714. 
[6] Hopkins, D. (1977). Methods of Generating Land Suitability Maps. Journal of American Institute and Planners, 43, pp. 386-398.

[7] McHarg, I. (1969). Design with Nature. New York: The Natural History Press, pp. 130-143.

Michael, B., Yichun, X. (2001). Modeling inside GIS: Part 2. Selecting and Celebrating Urban models using ARC-Info. International Journal of Geographic Information Science,8(5), pp. 457-470.

[8] httpp://www.skijalistasrbije.rs/sr/o-centru-kopaonik/, retrieved 20 December 2014. [9] Jovičić Ž. (1990). The selection of the site as a factor in the rational use of space vital physical and geographical elements. Procedeengs of papers „, Nature of Mountain Kopaonik -protection and using", Institute for Tourism Faculty of Natural Science and Mathematics , 21, pp. 313-315.

[10] Vasović, M. (1990). Threats and the use of the mountain nature with special goals on the Mountain Kopaonik. Procedeengs of papers „, Nature of Mountain Kopaonik protection and using ", Institute for Tourism Faculty of Natural Science and Mathematics, 29, pp. 123-129. 